\title{
Tamarixia radiata (Waterston) and Cheilomenes sexmaculata (Fabricius) as biological control agents of Diaphorina citri Kuwayama in Ecuador
}

Yilda Chavez ${ }^{1}$, Dorys T. Chirinos ${ }^{1,2 *}$, Guillermo González ${ }^{3}$, Nestor Lemos ${ }^{1}$, Adrian Fuentes ${ }^{1}$, Rossana Castro ${ }^{1}$, and Takumasa Kondo ${ }^{4}$

\section{ABSTRACT}

Diaphorina citri Kuwayama (Hemiptera: Liviidae) is the main vector of the bacteria that causes Huanglongbing (HLB), the most destructive disease of Citrus. The presence of D. citri was reported in Ecuador in 2013 on branches of citrus, Citrus spp., and orange jessamine, Murraya paniculata (L.) Jack (Rutaceae), but HLB has not been detected so far in this country. This paper reports for the first time the presence of two important natural enemies of $D$. citri in Ecuador, i.e., its main parasitoid Tamarixia radiata (Waterston, 1922) (Hymenoptera: Eulophidae) and the adventitious ladybird beetle Cheilomenes sexmaculata (Fabricius, 1781) (Coleoptera: Coccinellidae) attacking psyllid nymphs on M.paniculata, in Guayaquil, Guayas province, Ecuador. A short diagnosis of the two natural enemies and their distribution in the New World is presented based on published literature.

Key words: Asian citrus psyllid, biological control, Diaphorina citri, Ecuador, parasitoid, predator.

${ }^{1}$ Universidad Agraria del Ecuador, Facultad de Ciencias Agrarias, P.O. box 09-04-100, Guayaquil, Ecuador.

${ }^{2}$ Universidad del Zulia, Facultad de Agronomía, Apartado Postal 15205, Maracaibo, 4005, Zulia, Venezuela.

"Corresponding author (dtchirinos@gmail.com).

${ }^{3}$ Independent Researcher, Nocedal 6455 La Reina, Santiago, Chile. ${ }^{4}$ Corporación Colombiana de Investigación Agropecuaria (CORPOICA), Calle 23, Carrera 3, Continuo al Penal, Palmira, Valle, Palmira, Colombia.

Received: 24 November 2016.

Accepted: 24 March 2017.

doi:10.4067/S0718-58392017000200180

\section{INTRODUCTION}

The citrus industry like other agricultural activities is affected by the proliferation of insect pests that limit its yield. One of the most important problems worldwide is the disease known as citrus greening or Huanglongbing (HLB). HLB is probably the most serious citrus disease, even more serious than the Citrus tristeza virus, and thus posing a threat to regions that are still free of the disease (Bové, 2006). In the New World, HLB is caused by the phloem-limited bacteria Candidatus Liberibacter asiaticus and $C$. Liberibacter americanus that are associated with the excessive production of starch in plants, resulting in clogging of the phloem and eventual death of the plant (Bové, 2006). The Asian citrus psyllid (ACP), Diaphorina citri Kuwayama (Hemiptera: Liviidae), is the main vector in America and Asia of the bacteria that causes HLB (Bové, 2006). This insect has a wide distribution and an extensive list of host plants in about 25 genera in the family Rutaceae. Although the disease has not been found, $D$. citri was first detected in Ecuador in 2013 on branches of citrus, Citrus spp., and orange jessamine, Murraya paniculata (L.) Jack (Rutaceae), in Guayaquil, Samborondón and Duran (Cornejo and Chica, 2014).

Herein we report the presence of Tamarixia radiata (Waterston, 1922) (Hymenoptera: Eulophidae) (Figure 1A-1C) for the first time in Ecuador based on parasitoid specimens found naturally parasitizing nymphs of $D$. citri. Tamarixia radiata was first described by Waterston (1922) in the genus Tetrastichus Haliday, based on specimens collected in Punjab Province, northwest India, currently part of Pakistan (Parra et al., 2016). Subsequently, Graham (1987) transferred it to the genus Tamarixia Mercet. The adult parasitoids are small wasps (0.92 to $1.04 \mathrm{~mm}$ in length) with widely separated eyes, and the head proportionally wider than long; the wings are hyaline with pale yellow veins. There is a strong sexual dimorphism, in which males are slightly smaller in total length and wing extension, with the antennae covered by long and fine setae and being 1.5 times longer than those of the females (Kondo et al., 2012). Tamarixia radiata can be differentiated from closely related species by the following combination of features: (i) Wing speculum with sparse setae, (ii) femora and tibia usually completely yellow (at most slightly darkened dorsally), (iii) propodeal disc smooth and without a carina between the spiracle and median carina, and (iv) abdomen dark laterally and dorsomedially yellow (less pronounced and more anterior in male) (Kondo et al., 2012). 
Figure 1. A. Infestation of Diaphorina citri with various psyllid nymphs, some showing exit holes of the parasitoid Tamarixia radiata. B. Adult wasp of $T$. radiata underneath the mummified nymph of $D$. citri just before emergence. C. Adults of $T$. radiata. D. Pupa of Cheilomenes sexmaculata. E. Adult C. sexmaculata, "quadriplagiata" color form. F. Adult C. sexmaculata, "sexmaculata" color form.

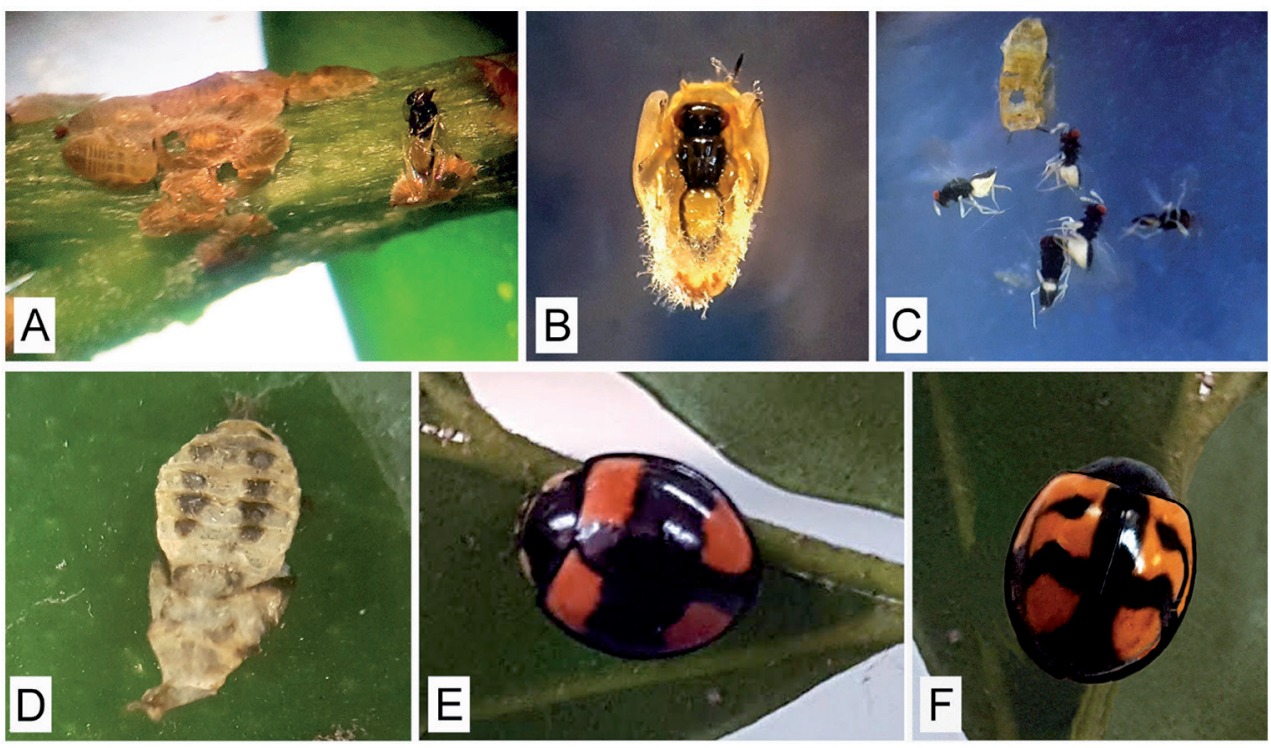

10X for $\mathrm{A}$ and $\mathrm{C} ; 40 \mathrm{X}$ for $\mathrm{B}, \mathrm{D}, \mathrm{E}$ and $\mathrm{F}$.

Source: Photos by D.T. Chirinos.

Tamarixia radiata (Fabricius, 1781) is an idiobiont ectoparasitoid specific to $D$. citri, with arrhenotokous reproduction, i.e., unfertilized eggs produce male progeny; females generally lay one or two eggs at most on the venter of the psyllid, generally between the third pair of legs; if two eggs are laid, only one of the two larvae that hatches will develop into adulthood due to cannibalism (Parra et al., 2016). When the egg hatches, the larva begins feeding on the hemolymph of the host and at the end of this phase, it attaches the remains of the psyllid nymph to the plant in order to create a shield when it turns into a pupa (Parra et al., 2016). Tamarixia radiata attacks third-, fourth- and fifth-instar nymphs of $D$. citri with a marked preference for fourth- and fifth-instar nymphs, depending on the study (Parra et al., 2016). Tamarixia radiata is considered an important mortality factor of this psyllid, which is why it has been used in several biological control programs (Etienne et al., 2001; Pluke et al., 2008; Hoddle, 2012). In the New World, T. radiata has been reported in the following countries: Argentina (Lizondo et al., 2007), Belize (Lopez et al., 2014), Brazil (Gómez-Torres et al., 2006), Colombia (Ebratt et al., 2011), Costa Rica (Qureshi and Stansly, 2010), Cuba (Peralta, 2002), Ecuador (present study), El Salvador (Hernández, 2016), Guadeloupe (Etienne et al., 2001), Honduras (Agostini, 2011), Jamaica (Chen and Stansly, 2014), Mexico (González-Hernández et al., 2009), Nicaragua (Agostini, 2011), Panama (Arredondo-Bernal et al., 2013), Paraguay (De Leon et al., 2010), Puerto Rico (Pluke et al., 2008), Uruguay (De Leon et al., 2010), USA (Skelley and Hoy, 2004; Léon and Sétamou, 2010; Hoddle, 2012), and Venezuela (Cermeli et al., 2007).
Another natural enemy, Cheilomenes sexmaculata Fabricius (Coleoptera: Coccinellidae) (Figure 1D-1F) also was found feeding upon $D$. citri. Cheilomenes sexmaculata is a species of ladybird beetle originally reported from India and the Oriental region and Australia (Agarwala and Yasuda, 2000). In Asia, C. sexmaculata is known to occur in China (Lin et al., 1973), Taiwan (Chien and Chu, 1996), India (Husain and Nath, 1927) and Iran (Rakhshani and Saeedifar, 2013). In South America, C. sexmaculata is an adventitious species, recorded from Chile (González, 2006), Colombia (Kondo et al., 2015), Peru (González, 2007) and Venezuela (Angulo et al., 2011). It was first reported in Ecuador by Cornejo and González (2015) in the province of Guayas, in a mangrove growing area on hibiscus leaves, Hibiscus tiliaceus L. var. pernambucensis (Arruda) I.M. Johnst. (Malvaceae), feeding on secretions from linear nectaries found on the leaf veins. Despite the occasional feeding from extrafloral nectaries already mentioned above, the species is an excellent aphid predator. Biological aspects of $C$. sexmaculata feeding on Aphis craccivora Koch were studied in Venezuela (Angulo et al., 2011). Worldwide, $C$. sexmaculata has been observed preying on more than 70 species of aphids, as well as many species of psyllids (Psyllidae), whiteflies (Aleyrodidae), mealybugs (Pseudococcidae), lace bugs (Tingidae), leafhoppers (Cicadellidae), plant hoppers (Fulgoroidea), spider mites (Acari), and early stages of butterfly larvae (Lepidoptera) (Agarwala and Yasuda, 2000). Cheilomenes sexmaculata has an extremely variable design, ranging from almost totally black to specimens with yellow elytra with just a black sutural stripe. The pronotum also may be almost 
totally black, or have clear areas at the base, with margins and a discal projection that goes from the anterior angles to almost the center of the disc. Specimens found in South America also have fairly variable designs.

The objective of this paper was to report the first known presence in Ecuador of two natural enemies of D. citri: Tamarixia radiata, a specific parasitoid of the Asian citrus psyllid, and a generalist predator, the ladybird beetle Cheilomenes sexmaculata. We provided also brief information on their distribution in the New World and their morphology based on published literature.

\section{MATERIALS AND METHODS}

A search for natural enemies of D. citri was carried out in April, June and October 2016, in Los Samanes Park (0206'13.9' N, 7954'12.3' W, 4.5 m a.s.1.), Guayaquil, province of Guayas, Ecuador. Predatory insect larvae were collected in situ and taken alive (together with their prey) to the laboratory in order to allow them to reach the adult stage and facilitate their identification. For the collecting of parasitoids, on each collecting trip, 20-40 samples of young branches about $10 \mathrm{~cm}$ long of $M$. paniculata infested with different stages of development (eggs, nymphs and adults) of D. citri were collected. Psyllid nymphs present on these branches were observed under a stereoscope with 10 to $40 \mathrm{X}$ magnification (Motic SMZ 140 series, Hong Kong, China) and separated into three categories: (i) non-parasitized nymphs (nymphs with yellowish coloration), (ii) parasitized nymphs (nymphs with a brownish coloration, showing typical symptoms of a mummified nymph, without exit holes), and (iii) mummified nymphs with exit holes. A total of three collecting trips were carried out, in April, June and October 2016, respectively. For each collection, the number of non-parasitized (category i) and parasitized psyllid nymphs (categories ii and iii) was counted and the rate of parasitization was calculated by dividing the number of parasitized nymphs by the total number of nymphs sampled, multiplied by 100 .

The mummified nymphs were removed from the branches and placed individually in transparent gelatin capsules for the eventual emergence of adult parasitoids. After separating the psyllid nymphs with symptoms of parasitization, branches were placed in entomological cages in order to obtain adult parasitoids from any overlooked parasitized psyllid nymphs. The emerged adult parasitoids (males and females) were identified using the characteristics given by Graham (1987) and Kondo et al. (2012). The coccinellid Cheilomenes sexmaculata was identified by comparing its morphology and design with specimens deposited in the private collection of Guillermo González (Santiago, Chile), for which specimens were identified from the genitalia based on descriptions and images by Iablokoff-Khnzorian (1982). All studied material is deposited in the entomological collection of the Facultad de Ciencias Agrarias de la Universidad Agraria del Ecuador, Guayaquil, Ecuador.

\section{RESULTS AND DISCUSSION}

Only old parasitized nymphs (psyllid mummies) with exit holes were obtained in samples of plant material collected in April and June 2016, and for these first two collections no adult parasitoid wasps were collected. However, by the position of the exit holes on the anterior part of the parasitized nymphs, the presence of $T$. radiata was suspected, because this is a characteristic feature of this parasitoid according to Etienne et al. (2001). Parasitism rates were $11.9 \%(\mathrm{n}=1044)$ in April and $21.5 \%(\mathrm{n}=709)$ in June.

In October, adult parasitoid wasps of $T$. radiata were obtained from mummified nymphs of $D$. citri (Figure 1A1C). On the underside of the mummified nymphs, pupae and fully-developed parasitoids (Figure 1B) were observed. As the parasitoid larva develops underneath the body of its host, the psyllid nymph becomes brownish and eventually dries out; the adults of T. radiata (Figure 1C) emerge through a hole on the thorax at the anterior part of the body (Figure 1A) (Parra et al., 2016). The parasitism rate in October was $81.1 \%$ $(n=1655)$. The morphological features of the adult parasitoid wasps (males and females) coincide with the diagnoses of $T$. radiata provided by various authors (Graham, 1987; Cermeli et al., 2007; Ebratt et al., 2011; Kondo et al., 2012).

A ladybird beetle, C. sexmaculata, also was found feeding on psyllid nymphs of $D$. citri. Two forms of $C$. sexmaculata were observed in the present study; one corresponds to what is known as "quadriplagiata" in which there is a design made up of four large red markings delimited by a large black cross and a thin border of the same color on the elytra (Figure 1E); and the "sexmaculata" form that gives the name to the species epithet, with red elytra and six black spots in each elytron that form three irregular transverse bands in zigzag (Figure 1F).

The increase in the parasitism rates from April to October (11.9\% to $81.1 \%$ ) suggests that the parasitoid may have already arrived to the studied area in Ecuador by the end of 2015, gradually beginning its colonization process. Currently, T. radiata has fully established as a natural enemy there. The presence of this specific parasitoid T. radiata, and the generalist predator $C$. sexmaculata, probably explains why high populations of this psyllid have not been observed despite its recent introduction. Thus, we suggest the great importance of the biological control exerted by these and other natural enemies in the control of populations of $D$. citri in Ecuador. This is similar to a situation reported for Venezuela, where low populations were attributed to the control by T. radiata (Cermeli et al., 2007). According to a study conducted in India, $C$. sexmaculata, $T$. radiata and the lacewing Mallada boninensis (Okamoto) (Neuroptera: Chrysopidae) are the three most effective natural enemies of D. citri (Shivankar and Rao, 2010). Diaphorina citri was detected in Ecuador in 2013 (Cornejo and Chica, 2014) but until now no natural enemies of this important insect pest were found. To our knowledge, this is the first official report of $T$. radiata and $C$. sexmaculata as natural enemies of $D$. citri in Ecuador. 


\section{CONCLUSIONS}

Herein we report two important natural enemies, Cheilomenes sexmaculata and Tamarixia radiata, for the first time in Ecuador, preying upon and parasitizing psyllid nymphs of Diaphorina citri, respectively. As a result of this study, the distribution of $T$. radiata in the New World is updated to include Argentina, Belize, Brazil, Colombia, Costa Rica, Cuba, Ecuador, El Salvador, Guadeloupe, Honduras, Jamaica, Mexico, Nicaragua, Panama, Paraguay, Puerto Rico, Uruguay, USA and Venezuela.

\section{ACKNOWLEDGEMENTS}

Many thanks to Penny Gullan (The Australian National University, Canberra, Australia) for kindly reviewing the manuscript and the English text.

\section{REFERENCES}

Agarwala, B.K., and Yasuda, H. 2000. Competitive ability of ladybird predators of aphids: A review of Cheilomenes sexmaculata (Fabr.) (Coleoptera: Coccinellidae) with a worldwide checklist of preys. Journal of Aphidology 14:1-20.

Agostini, J.P. 2011. Cítricos: El HLB y su prevención. Revista de Investigaciones Agropecuarias N³7. p. 677.

Angulo, J., Arcaya, E., y González, R. 2011. Aspectos biológicos de Menochilus sexmaculatus (F.) (Coleoptera: Coccinellidae) alimentado con Aphis craccivora Koch (Hemiptera: Aphididae). Boletín del Centro de Investigaciones Biológicas (Maracaibo, Venezuela) 45(4):423-431.

Arredondo-Bernal, H.C., Sánchez-González, J.A., y MellínRosas, M.A. 2013. Taller subregional de control biológico de Diaphorina citri, vector del HLB. p. 61. Oficina Subregional de la FAO para Mesoamérica, Ciudad de Panamá, Panamá.

Bové, J.M. 2006. Huanglongbing: A destructive, newly-emerging, century-old disease of citrus. Journal of Plant Pathology 88:7-37.

Cermeli, M., Morales, P., Perozo, J., y Godoy, F. 2007. Distribución del psílido asiático de los cítricos Diaphorina citri Kuwayama (Hemiptera, Psyllidae) y presencia de Tamarixia radiata (Waterston) (Hymenoptera, Eulophidae) en Venezuela. Entomotropica 22:181-184.

Chen, X., and Stansly, P. 2014. Biology of Tamarixia radiata (Hymenoptera: Eulophidae), parasitoid of the citrus greening disease vector Diaphorina citri (Hemiptera: Psylloidea): a mini review. Florida Entomologist 97:1404-1413.

Chien, C.C., and Chu, Y.I. 1996. Biological control of citrus psyllid, Diaphorina citri in Taiwan. p. 93-105. Biological Pest Control in Systems of Integrated Pest Management-1996. Food and Fertilizer Technology Center Book Series No. 47. Food and Fertilizer Technology Center, Taipei, Taiwan.

Cornejo, J.F., and Chica, E.J. 2014. First record of Diaphorina citri (Hemiptera: Psyllidae) in Ecuador infesting urban citrus and orange jasmine trees. Journal of Insect Science 14(298):1-3.

Cornejo, X., y González, G. 2015. Contribución al conocimiento de la fauna entomológica de los manglares: Olla roatanensis Vandenberg y Cheilomenes sexmaculata Fabricius, dos nuevos registros de Coleoptera: Coccinellidae para Ecuador y Perú. Revista Científica de Ciencias Naturales y Ambientales (Ecuador) 8(2):76-80.
De Leon, J.H., Gastaminza, G.A., Parra, J.R., Setamou, M., Logarzo, G., Buenahora, J., et al. 2010. Extensive haplotype variation in Tamarixia radiata populations from the Americas: multiple groups. p. 59-66. In VI Congreso Argentino de Citricultura, San Miguel de Tucumán. 2-4 June 2010. Asociación Tucumana del Citrus (ATC) y Estación Experimental Agroindustrial Obispo Colombres (EEAOC), Tucumán, Argentina.

Ebratt, E.E., Rubio, L.T., Costa, V.A., Zambrano Gómez, E.M., Castro, A.P., y Santamaría, M.Y. 2011. Primer registro de Tamarixia radiata (Waterston, 1922) (Hymenoptera: Eulophidae) en Colombia. Revista Facultad Nacional de Agronomía 64:6141-6146.

Etienne, J., Quilici, S., Marvival, D., and Franck, A. 2001. Biological control of Diaphorina citri (Hemiptera: Psyllidae) in Guadeloupe by imported Tamarixia radiata (Hymenoptera: Eulophidae). Fruits 56:307-315.

Gómez-Torres, M.L., Nava, D.E., Gravena, S., Costa, V.A., e Parra, J.R.P. 2006. Primeiro registro de Tamarixia radiata (Waterston) (Hymenoptera: Eulophidae) em Diaphorina citri Kuwayama (Hemiptera: Psyllidae) no Brasil. Revista de Agricultura (Piracicaba) 81:112-116.

González, G. 2006. Los Coccinellidae de Chile [online]. Available at http://www.coccinellidae.cl/paginasWebChile/ PaginasOriginal/cheilomenessexmaculata.php (accessed November 2016).

González, G. 2007. Coccinellidae de Perú [online]. Available at http://www.coccinellidae.cl/paginasWebPeru/Paginas/ InicioPeru.php (accessed November 2016).

González-Hernández, A., Arredondo-Bernal, H.C., RoblesGonzález, M., Martínez-Carrillo, J.L., Pérez, J.Y., y LópezArroyo, J.I. 2009. Determinación de especies de parasitoides del psílido asiático de los cítricos Diaphorina citri (Hemiptera: Psyllidae) en México. Entomología Mexicana 8:373-377.

Graham, M.W.R.V. 1987. A reclassification of the European Tetrastichinae (Hymenoptera: Eulophidae), with a revision of certain genera. Bulletin of the British Museum (Natural History). Entomology 55:1-392.

Hernández, R.Y. 2016. Inventario de enemigos naturales asociados a Diaphorina citri (Kuwayama, 1907) (Hemiptera: Psyllidae), en dos fincas de producción citrícola en el departamento de San Salvador, El Salvador. Bachelor thesis. Universidad de El Salvador, San Salvador, El Salvador.

Hoddle, M.S. 2012. Foreign exploration for natural enemies of Asian citrus psyllid, Diaphorina citri (Hemiptera: Psyllidae), in the Punjab of Pakistan for use in a classical biological control program in California USA. Pakistan Entomologist 34:1-5.

Husain, M.A., and Nath, D. 1927. The citrus psylla (Diaphorina citri Kuw.) (Psyllidae: Homoptera). Memoirs of the Department of Agriculture in India, Entomology Series 10:5-27.

Iablokoff-Khnzorian, S.M. 1982. Les coccinelles ColeoptèresCoccinellidae: Tribu Coccinellini des regions Palearctique et Orientale. Boubée, Paris, France.

Kondo, T., González, G., Tauber, C., Guzmán-Sarmiento, Y.C., Vinasco Mondragon, A.F., and Forero, D. 2015. A checklist of natural enemies of Diaphorina citri Kuwayama (Hemiptera: Liviidae) in the department of Valle del Cauca, Colombia and the World. Insecta Mundi 0457:1-14.

Kondo, T., Quintero, E.M., Campuzano, M., Wyckhuys, K.A.G., and Heraty, J. 2012. First report of Tamarixia radiata (Waterston) (Hymenoptera: Eulophidae), a parasitoid of the Asian citrus psyllid Diaphorina citri Kuwayama (Hemiptera: Psyllidae) in the department of Valle del Cauca, Colombia. Boletín del Museo de Entomología de la Universidad del Valle 13(1):48-51. 
Léon, J.H., and Sétamou, M. 2010. Molecular evidence suggests that populations of the Asian citrus psyllid parasitoid Tamarixia radiata (Hymenoptera: Eulophidae) from Texas, Florida, and Mexico represent a single species. Annals of the Entomological Society of America 103(1):100-110.

Lin, S.J., Ke, Y.F., and Tao, C.C. 1973. Bionomics observation and integrated control of citrus psylla, Diaphorina citri Kuwayama. Journal of Horticultural Society of China 19:234-242.

Lizondo, M., Gastaminza, G., Costa, A., Augeir, L., Goméz, M., and Willink, M. 2007. Records of Tamarixia radiata (Hymenoptera: Eulophidae) in northwestern Argentina. Revista Industrial y Agricola de Tucumán 84:21-22.

Lopez, V., Moore, K., Garcia, M., and Manzanero-Majil, V. 2014. Manual for the mass production of the parasitoid Tamarixia radiata on its host, Diaphorina citri (Asian citrus psyllid), cultured on Murraya paniculata (Orange Jasmine) in Belize. Food and Agriculture Organization of the United Nations, Belize.

Parra, J.R., Alves, G., Diniz, A.J., and Vieira, J. 2016. Tamarixia radiata (Hymenoptera: Eulophidae) $\times$ Diaphorina citri (Hemiptera: Liviidae): mass rearing and potential use of the parasitoid in Brazil. Journal of Integrated Pest Management 7:1-11.

Peralta, E.L. 2002. Principales enfermedades emergentes que amenazan la citricultura de los países del Caribe. Taller sobre plagas emergentes de los cítricos. Revista de Protección Vegetal $17: 193-202$.
Pluke, R.W., Qureshi, J.A., and Stansly, P.A. 2008. Citrus flushing patterns, Diaphorina citri (Hemiptera: Psyllidae) populations and parasitism by Tamarixia radiata (Hymenoptera: Eulophidae) in Puerto Rico. Florida Entomologist 91:36-42.

Qureshi, J.A., and Stansly, P.A. 2010. Tamarixia radiata Waterston [Hymenoptera: Eulophidae], an ectoparasitoid of Diaphorina citri Kuwayama [Hemiptera: Psyllidae]. Available at https:// biocontrol.entomology.cornell.edu/parasitoids/Tamarixia.php (accessed November 2016).

Rakhshani, E., and Saeedifar, A. 2013. Seasonal fluctuations, spatial distribution and natural enemies of Asian citrus psyllid Diaphorina citri Kuwayama (Hemiptera: Psyllidae) in Iran. Entomological Science 16:17-25.

Shivankar, V.J., and Rao, C.N. 2010. Psyllids and their management. Pest Management in Horticultural Ecosystems 16(1):1-4.

Skelley, L.H., and Hoy, M.A. 2004. A synchronous rearing method for the Asian citrus psyllid and its parasitoids in quarantine. Biological Control 29:14-23. 